\title{
Panda sign due to severe coughing
}

IJM Reid, ${ }^{2} \mathrm{D}$ Williams

${ }^{1}$ Consultant Neurologist, Aberdeen Royal Infirmary, Foresterhill, Aberdeen; ${ }^{2}$ Consultant General Physician, Dr Gray's Hospital, Elgin, UK

\begin{abstract}
We present the case of a patient who developed periorbital ecchymosis (panda sign) following an exacerbation of asthma with severe coughing.There was no history of cranial trauma. Investigations for a structural or haematological cause were negative. The panda sign is typically seen following a base of skull fracture, but rarely reported due to severe coughing.
\end{abstract}

KEYWORDS Panda sign, periorbital ecchymosis, raccoon eyes

\author{
Correspondence to J Reid \\ Ward 40, Aberdeen \\ Royal Infirmary, \\ Foresterhill, Aberdeen \\ AB25 2ZN, UK
}

tel. +44 (0) I 224554922

e-mail johnreid I@nhs.net

DECLARATION OF INTERESTS No conflicts of interest declared.

\section{CASE HISTORY}

A 19-year-old woman developed severe coughing during an asthma exacerbation. Within 48 hours she developed bilateral sub-conjunctival haemorrhages and periorbital ecchymosis (known as 'panda sign' or 'raccoon eyes' in North America) (Figure I). There was no prior history of head trauma or excessive bleeding. Full blood count, clotting profile, platelet studies and serum electrophoresis were normal. Computed tomography (CT) and magnetic resonance (MRI) brain scans were normal with no evidence of base of skull fracture and no abnormality in the intracranial or periorbital vasculature. The ecchymosis resolved after two weeks.

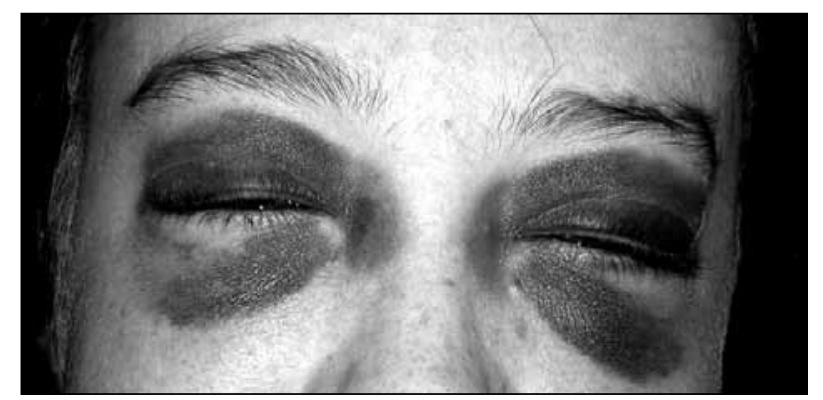

FIGURE I Patient with severe periorbital ecchymoses and oedema.

\section{DISCUSSION}

We report periorbital ecchymosis (i.e. panda sign) following severe coughing in a patient with no bleeding disorder.This sign typically occurs following base of skull fracture,' where classically there is sparing of the tarsal plate, but can occur following thoracic trauma, ${ }^{2}$ rhinoplasty, with bleeding disorders ${ }^{3}$ or as a presenting feature of amyloidosis ${ }^{4}$ or neuroblastoma. ${ }^{5}$ One case reports its occurrence following sneezing, ${ }^{6}$ and another following severe adenovirus infection in a child. ${ }^{7}$ Other rare reported associations include with a trigeminal autonomic cephalalgia, ${ }^{8}$ giant cell arteritis, ${ }^{9}$ minor periorbital trauma ${ }^{10}$ and Kaposi's sarcoma." In this case it is presumed that severely raised venous pressure due to valsalva and coughing has caused periorbital venous haemorrhage. This widens the differential diagnosis of causes of periorbital ecchymosis, ranging from benign to life-threatening.

\section{REFERENCES}

I McPheeters RA, White S, Winter A. Raccoon eyes. West J Emerg Med 2010; $11: 97$.

2 Deakin CD. Bilateral periorbital hematoma (raccoon eyes) following thoracic crush injuries: case reports. J Trauma 1995; 38:816-7. http://dx.doi.org/10.1097/00005373-199505000-00025

3 Kumar V, Ghosh B, Raina UK et al. Bilateral periorbital ecchymosis in a case with dengue fever. Indian J Ophthalmol 2009; 57: 242-3. http://dx.doi.org/I0.4103/0301-4738.49407

4 Weingarten TN, Hall BA, Richardson BF et al. Periorbital ecchymoses during general anesthesia in a patient with primary amyloidosis: a harbinger for bleeding? Anesth Analg 2007; I 05: 156 I3. http://dx.doi.org/I0.1213/0I.ane.0000290304.02 I25.6e

5 Moran DE, Donoghue V. Periorbital ecchymosis ('raccoon eyes') as the presenting feature of neuroblastoma. Pediatr Radiol 2010; 40: I7I0. http://dx.doi.org//0.1007/s00247-009-1467-3

6 Maramattom BV. Raccoon eyes following vigorous sneezing. Neurocrit Care 2006;4: I I I-2.http://dx.doi.org// 0.I385/NCC:4:2:I5I

7 Chuang YY, Chiu CH, Wong KS et al. Severe adenovirus infection in children.J Microbiol Immunol Infect 2003; 36:37-40.

8 Attanasio A, D'Amico D, Frediani $F$ et al. Trigeminal autonomic cephalgia with periorbital ecchymosis, ocular hemorrhage, hypertension and behavioral alterations. Pain 2000; 88:109-12. http://dx.doi.org/I0.10I6/S0304-3959(00)00308-0

9 Fernandez S, Adhiyaman V. Giant cell arteritis presenting as periorbital ecchymosis. Age Ageing 2005; 34:85-6. http://dx.doi. org/10.1093/ageing/afh227

10 Kandogan T, Aydar L, Yalciner B. Bilateral black eyes, 'raccoon's eyes', resulting from plucking of eyebrows. Swiss Med Wkly 2005; 135:160.

II Schwartz RA, Spicer MS, Thomas I et al. Ecchymotic Kaposi's sarcoma. Cutis 1995; 56:104-6. 